\title{
ANALISIS CEMARAN LOGAM BERAT TEMBAGA (Cu) PADA AMDK DI DAERAH PANYILEUKAN DENGAN MENGGUNAKAN SSA
}

\author{
Ivan Andriansyah*, Anne Yuliantini, Avita Rischa Yunita \\ Program Studi S1 Farmasi Sekolah Tinggi Farmasi Bandung \\ *email: ivan.andriansyah@stfb.ac.id
}

Received 10 Mei 2019

Accepted 28 June 2019

\begin{abstract}
Abstrak
Air mineral merupakan salah satu kebutuhan manusia yang paling penting. Kebutuhan air minum dapat dipenuhi dari Air minum dalam kemasan (AMDK). Ada syarat yang harus dipenuhi oleh AMDK untuk menjamin kualitas air minum yang layak dikonsumsi. Salah satu syarat AMDK adalah tidak mengandung logam berat tembaga $(\mathrm{Cu})$ yang lebih dari 0,5 bpj. Tembaga termasuk logam yang dibutuhkan oleh tubuh dalam jumlah sedikit tetapi dalam jumlah yang berlebihan akan bersifat toksik. Oleh karena itu, diperlukan analisis kadar $\mathrm{Cu}$ pada AMDK khususnya di daerah Panyileukan guna menjamin kualitas AMDK. Penelitian ini terdiri dari 2 tahapan, yaitu validasi, penetapan kadar sampel menggunakan SSA pada panjang gelombang $324,75 \mathrm{~nm}$ dan statistika. Dari hasil validasi, didapatkan persamaan kurva kalibrasi $\mathrm{y}=0,1537 \mathrm{x}+0,0134$ dengan nilai koefisien korelasi (r) sebesar 0,998, batas deteksi dan kuantisasi berturut-turut sebesar 0,03 dan 0,12 bpj, persen perolehan kembali $0,5-1,7 \%$ dengan nilai SBR kurang dari $2 \%$. Hasil pengukuran kadar $\mathrm{Cu}$ pada AMDK berkisar antara 0,00100 - 0,00192 bpj. Dari data AMDK dapat dikatakan bahwa kadar $\mathrm{Cu}$ tidak melebihi ambang batas yang ditetapkan oleh SNI 01-3553-2006 yaitu $0,5 \mathrm{bpj}$.
\end{abstract}

Katakunci: Air mineral, Tembaga (Cu), SSA, Logam berat

\begin{abstract}
Mineral water is one of the most important human needs. There are requirements bottled drink mineral water to ensure quality and safety to consumed a mineral water. One of the requirements bottled drink mineral water is not containing copper $(\mathrm{Cu})$ more than $0,5 \mathrm{ppm}$. The small amounts of copper was needed in the body, but in the high amounts can be toxic. Therefore, to analyze the $\mathrm{Cu}$ rate in bottled drink mineral water especially in Panyileukan area to ensure quality of bottled drink mineral water. This research consists of 2 stages, validation and determination samples using SSA at wavelength $324,75 \mathrm{~nm}$. The validation result is calibration curve equation $\mathrm{y}=0,1537 \mathrm{x}+0,0134$ with correlation coefficient value (r) 0,998, detection and quantization limit are 0,03 and $0,12 \mathrm{ppm}$, percent recovery $0,5-1,7 \%$ with RSD value less than $2 \%$. The result of measurement of $\mathrm{Cu}$ rate in AMDK ranged from $0,00100-0,00192 \mathrm{ppm}$. The result of bottled drink mineral water that $\mathrm{Cu}$ are not exceed of threshold SNI 01-3553-2006 is 0,5 ppm.
\end{abstract}

Keywords: Bottled drink mineral water, Copper (Cu), SSA, Heavy metal 


\section{Pendahuluan}

Air merupakan salah satu kebutuhan primer bagi setiap makhluk hidup yang harus tersedia dalam kuantitas dan kualitas yang memenuhi syarat. Seluruh aktivitas manusia tidak pernah lepas dari air mulai masak, mandi, membersihkan rumah dan aktivitas lainnya. Air merupakan salah satu zat gizi makro esensial yang mempunyai beberapa fungsi yaitu sebagai pelarut, alat angkut, sebagai katalisator, pelumas, fasilitator pertumbuhan, dan pengatur suhu tubuh (Buanasita, et al., 2015).

Pertumbuhan jumlah penduduk yang semakin meningkat menjadikan kebutuhan serta permintaan air bersih meningkat pula termasuk kebutuhan air minum, di era yang serba instan ini banyak berbagai merk Air Minum Dalam Kemasan (AMDK) yang beredar di masyarakat. Hal ini dikarenakan AMDK memiliki kepraktisan yang lebih besar dibandingkan dengan air dalam gelas. Oleh karena itu, tingkat ketergantungan masyarakat terhadap AMDK semakin tinggi.

Air minum yang dikonsumsi harus memenuhi persyaratan yaitu tidak berwarna, tidak berasa, dan tidak berbau, serta tidak mengandung patogen yang berbahaya bagi kesehatan, tidak terdapat kandungan bahan kimia yang bisa mengubah fungsi tubuh dan dapat merugikan secara ekonomis (Slamet, 2004). Adapun persyaratan tersebut yaitu persyaratan fisik, kimia dan mikrobiologi. Hal ini berdasarkan Permenkes No. 416 Tahun 1990 tentang syarat-syarat dan pegawasan kualitas air. Air minum harus memenuhi persyaratan secara kimia yang meliputi derajat keasaman $(\mathrm{pH})$, kandungan bahan kimia organik, kandungan bahan kimia anorganik dan tingkat kesadahan (Yusnidar, 2012).

Menurut SNI 01-3553-2006 menyatakan bahwa batas maksimum cemaran logam berat tembaga $(0,5 \mathrm{mg} / \mathrm{L})$ pada AMDK, bahkan dalam Rancangan Standar Nasional Indonesia (RSNI-2, 2007) dalam Widaningrum (2007) menyatakan bahwa residu logam yang masih memenuhi standar Batas Maksimum Residu (BMR) untuk $\mathrm{Cu}$ adalah 50 ppm. Namun demikian pada logam tembaga $(\mathrm{Cu})$ merupakan konstituen yang harus ada dalam makanan manusia dan dibutuhkan oleh tubuh (Acceptance Daily Intake/ADI $=0,05$ $\mathrm{mg} / \mathrm{kg}$ berat badan).

Berdasarkan latar belakang tersebut, perlu dilakukan penelitian penentuan kadar logam tembaga terhadap AMDK yang beredar di Panyileukan. Dengan tujuan untuk menentukan cemaran logam tembaga pada AMDK yang beredar di daerah Panyileukan dengan metode SSA.

\section{Metode Penelitian}

Tahapan yang dilakukan pada penelitian ini meliputi: pengambilan sampel AMDK diambil disekitar Panyileukan yaitu 4 sampel AMDK dari kios-kios yang ada di panyileukan, pengolahan sampel, pembuatan larutan baku tembaga $(\mathrm{Cu})$, pembuatan kurva kalibrasi, validasi metode analisis dan analisis sampel.

Pengolahan sampel meliputi: penyiapan sampel, pemekatan sampel dari volume 250 menjadi $25 \mathrm{ml}$ dengan ditambahkan $\mathrm{HNO}_{3}$.

Validasi metode analisis meliputi: Perhitungan linieritas, batas deteksi (BD), batas kuantisasi (BK), akurasi dan presisi.

Analisis sampel dilakukan secara kuantitatif kemudian dibandingkan dengan batas yang diperbolehkan menurut SNI 01-3553-2006.

\section{Hasil dan Pembahasan}

Pada Penelitian ini dimaksudkan untuk mengetahui cemaran logam tembaga pada AMDK yang beredar di daerah panyileukan guna mengetahui kadar logam tembaga masih dalam batas yang ditetapkan atau melebihi batas.

Penetapan kadar tembaga $(\mathrm{Cu})$ pada AMDK dilakukan menggunakan instrumen Spektrofotometri Serapan Atom karena waktu pengerjaan yang cepat, sensitif dan sangat spesifik untuk unsur 
yang akan di analisis (Dewi,2011). Tahapan-tahapan yang dilakukan dalam penetapan kadar logam tembaga $(\mathrm{Cu})$ pada AMDK dimulai dengan pembuatan kurva kalibrasi, validasi metode analisis, destruksi sampel, dan penetapan konsentrasi logam tembaga $(\mathrm{Cu})$ pada sampel secara kuantitatif menggunakan instrumen spektrofotometri serapan atom.

Validasi metode analisis dilakukan untuk membuktikan bahwa metode yang digunakan dalam penelitian ini memenuhi persyaratan sehingga dapat dinyatakan bahwa data yang diperoleh selama penelitian merupakan hasil yang baik dan dapat dipercaya.
Uji linieritas suatu metode bertujuan untuk membuktikan adanya hubungan yang linier antara konsentrasi analit yang sebenarnya dengan respon alat.

Tabel 1. Nilai kalibrasi tembaga

\begin{tabular}{cc} 
Konsentrasi (ppm) & Absorbansi (y) \\
\hline 0,4 & 0,077 \\
0,5 & 0,090 \\
0,6 & 0,103 \\
0,7 & 0,120 \\
0,8 & 0,137 \\
0,9 & 0,153 \\
\hline
\end{tabular}

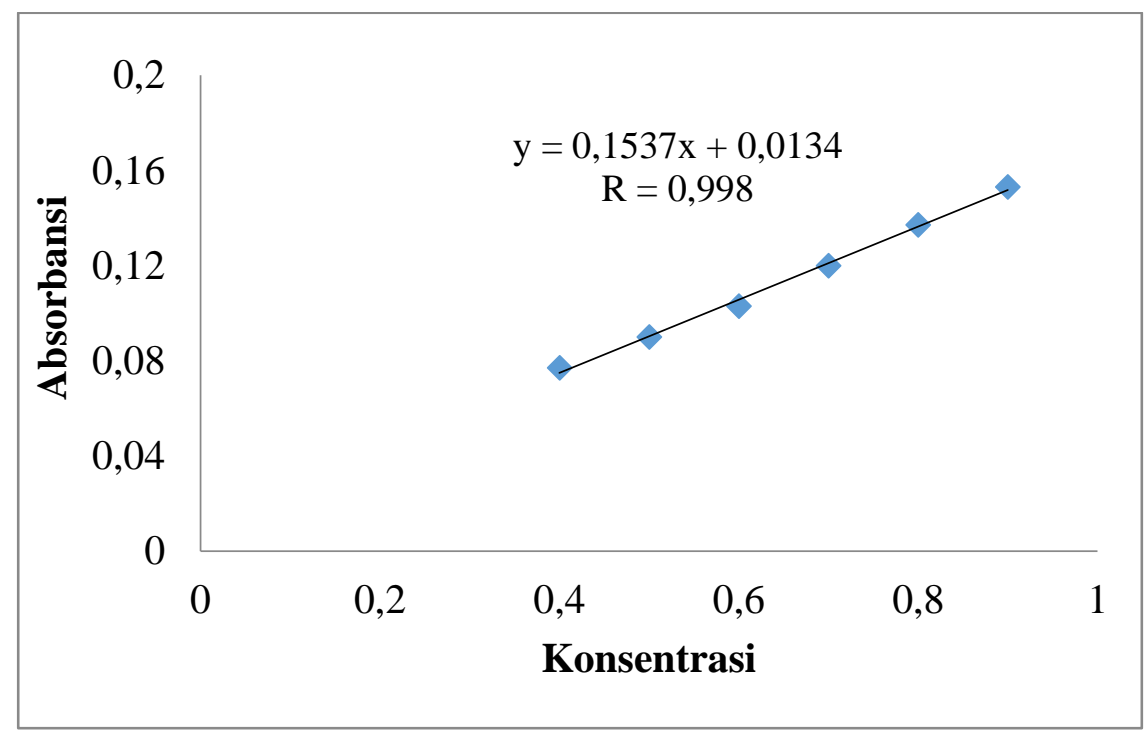

Gambar 1. Kurva kalibrasi tembaga

Kelinearitasan dilakukan dengan memperhatikan faktor-faktor kelinearan garis seperti nilai koefisien korelasi (r), koefisien determinasi $\left(\mathrm{R}^{2}\right)$, dan nilai $\mathrm{Vx} 0$. Dari data diatas diperoleh persamaan $\mathrm{y}=$ $0,1537 x+0,0134$ diperoleh nilai koefisien korelasi (r) sebesar 0,998. Hasil koefisien korelasi yang diperoleh dikatakan memenuhi syarat karena mendekati nilai 1 . Nilai koefisien determinasi (R2) yang diperoleh adalah 0,996.

Faktor kelinearitasan lainnya adalah Sx0 yaitu standar deviasi dari fungsi dengan nilai 0,012 dan koefisien korelasi dari fungsi $(\mathrm{Vx} 0)$ merupakan koefisien yang menentukan nilai linearitas suatu persamaan. Untuk nilai $\mathrm{Vx} 0$ diperoleh hasil $1,9 \%$, nilai ini tidak memenuhi syarat kelinearan garis yaitu $\leq 2 \%$, hasilnya dapat dilihat pada Tabel 2 .

Untuk akurasi atau kecermatan dinyatakan dalam uji perolehan kembali atau percent recovery. Presisi atau keseksamaan dinyatakan sebagai simpangan baku relatif (SBR). Akurasi dan presisi dilakukan pada sampel adisi dengan menambahkan larutan baku konsentrasi 0,5 ppm ke semua sampel, dilakukan sebanyak 5 kali pengukuran selama 2 hari (intraday dan interday). 
Tabel 2. Nilai BD dan BK

\begin{tabular}{ccccc}
\hline Konsentrasi (x) & Absorbansi $(\mathbf{y})$ & $\mathbf{y}^{\prime}(\mathbf{b x}+\mathbf{a})$ & $\left(\mathbf{y}-\mathbf{y}^{\mathbf{}}\right)^{\mathbf{2}}$ \\
\hline 0,4 & 0,077 & 0,07488 & $4,49 \mathrm{E}-06$ \\
0,5 & 0,090 & 0,09025 & $6,25 \mathrm{E}-08$ \\
0,6 & 0,103 & 0,10562 & $6,86 \mathrm{E}-06$ \\
0,7 & 0,12 & 0,12099 & $9,80 \mathrm{E}-07$ \\
0,8 & 0,137 & 0,13636 & $4,10 \mathrm{E}-07$ \\
0,9 & 0,153 & 0,15173 & $1,61 \mathrm{E}-06$ \\
& $\mathbf{X i}=\mathbf{0 , 6 5}$ & & & $\mathbf{\Sigma}=\mathbf{1 , 4 4 E - 0 5}$ \\
\hline $\mathbf{S y}$ & $\mathbf{B D}$ & $\mathbf{B K}$ & $\mathbf{S x 0}$ & $\mathbf{V x 0}$ \\
\hline 0,0018989 & 0,0370646 & 0,1235485 & 0,0123549 & 1,9
\end{tabular}

Tabel 3. Nilai rata-rata presisi dan akurasi intraday dan interday

\begin{tabular}{ccccc}
\hline $\begin{array}{c}\text { Nilai rata-rata } \\
\text { presisi dan akurasi }\end{array}$ & Sampel & $\begin{array}{c}\text { Konsentrasi } \\
\text { teoritis }\end{array}$ & $\begin{array}{c}\text { \% Perolehan } \\
\text { kembali }\end{array}$ & \% SBR \\
\hline Intraday & AMDK & $0,5 \mathrm{bpj}$ & 100,83 & 0,6915 \\
Interday & AMDK & $0,5 \mathrm{bpj}$ & 96,68 & 0,7207 \\
\hline
\end{tabular}

Dari data diatas hasil pengukuran dilakukan selama 2 hari, pada hari pertama AMDK nilai akurasi sebesar 100,83\% sedangkan pada hari kedua yaitu 96,68\%. Nilai akurasi tersebut pada sampel AMDK diperoleh nilai yang memenuhi syarat rentang yaitu $90-120 \%$, sedangkan data hasil pengukuran dan perhitungan presisi pada sampel AMDK di hari pertama diperoleh nilai \% SBR sebesar 0,691569\% dan pada hari kedua yaitu $0,720688 \%$.
Nilai presisi dari AMDK diperoleh nilai yang memenuhi syarat rentang yaitu $<2 \%$ (Harmita, 2004).

Pada penetapan kadar $\mathrm{Cu}$ sampel yang digunakan adalah 4 air minum dalam kemasan dan 4 air minum isi ulang yang dibedakan berdasarkan merk dan diberi kode Sampel $1-4$. Berikut adalah hasil pengukuran kadar sampel menggunakan spektrofotometri serapan atom.

Tabel 4. Kadar $\mathrm{Cu}$ dalam sampel AMDK

\begin{tabular}{ccc}
\hline Sampel AMDK & Kadar Cu (bpj) & Persyaratan menurut SNI \\
\hline 1 & 0,00192 & $0,5 \mathrm{bpj}$ \\
2 & 0,00100 & $0,5 \mathrm{bpj}$ \\
3 & 0,00149 & $0,5 \mathrm{bpj}$ \\
4 & 0,00111 & $0,5 \mathrm{bpj}$ \\
\hline
\end{tabular}

Data hasil pengukuran kadar $\mathrm{Cu}$ pada AMDK berkisar antara 0,00100 - 0,00192 bpj, maka AMDK tersebut dapat dikatakan bahwa kadar $\mathrm{Cu}$ tidak melebihi ambang batas yang ditetapkan oleh SNI 01-35532006 yaitu $0,5 \mathrm{bpj}$.
Beberapa logam dibutuhkan tubuh untuk membantu proses metabolisme tubuh tetapi jika mempunyai konsentrasi yang terlalu tinggi akan menyebabkan bioakumulasi (peningkatan konsentrasi) dan berbahaya bagi kesehatan. Salah satu 
logam yang dibatasi dalam jumlah kecil pada AMDK adalah tembaga $(\mathrm{Cu})$ apabila masuk ke dalam tubuh lebih dari ambang batas dapat menyebabkan terjadinya hepatic hepatic cirrhosis, kerusakan pada otak dan demyelinasi, serta terjadinya penurunan kerja ginjal (Palar, 2008).

\section{Kesimpulan}

Dalam penelitian yang dilakukan di dapatkan hasil bahwa teknik spektrofotometri serapan atom dapat

\section{Daftar Pustaka}

Buanasita, A., Yanto, A., Sulistyowati, I., 2015, Perbedaan Tingkat Konsumsi Energi, Lemak, Cairan, dan Status Hidrasi Mahasiswa Obesitas dan Non Obesitas, Indonesian Journal of Human Nutrition, Vol. 2(1): 11-22.

Dewi, 2011, Analisis Cemaran Logam Timbal (Pb), Tembaga (Cu), Kadmium (Cd) Dalam Tepung Gandum Secara Spektrofotometri Serapan Atom, Skripsi, Fakultas MIPA: Universitas Indonesia.

Harmita, 2004, Petunjuk Pelaksaan Validasi Metoda dan Cara Perhitungannya, Review Artikel, Majalah Ilmu Kefarmasian, Vol. 1(3).

Palar, H., 2008, Pencemaran dan Toksikologi Logam Berat, Rineka Cipta, Jakarta.

Slamet, J.S., 2004, Kesehatan Lingkungan, Yogyakarta: Gadjah Mada University Press.

Widaningrum, et al., 2007, Bahaya Kontaminasi Logam Berat dalam Sayuran dan Alternatif Pencegahan Cemarannya, Buletin Teknologi Pascapanen Pertanian, Vol. 3: 16-27.

Yusnidar, Y., 2012, Teknologi Pengolahan Air Tanah Sebagai Sumber Air Minum pada Skala Rumah Tangga, SIGMA Journal, 4(2): 63-7. digunakan untuk menganalisis logam $\mathrm{Cu}$ dalam Air minum dalam kemasan dengan nilai r yaitu 0,998 . Metode yang digunakan dapat diukur dengan batas deteksi 0,03 bpj. Pada analisis kandungan sampel dengan kadar tertinggi pada AMDK yaitu sampel 1 sebesar 0,00192 bpj dan kadar terkecil pada sampel 2 yaitu $0,00100 \mathrm{bpj}$. Dari data AMDK masih memenuhi standar yang di syaratkan dalam Standarisasi Nasional Indonesia yaitu sebesar $0,5 \mathrm{bpj}$. 